\title{
IL7：招請講演 7
}

24 日（日）第 1 会場

\section{The changing faces of vesicoureteral reflux \\ - then and now}

Division of Urology, The Children's Hospital of Philadelphia, Philadelphia /

Urology and Surgery, The University of Pennsylvania, School of Medicine, Pennsylvania, USA Michael C. Carr

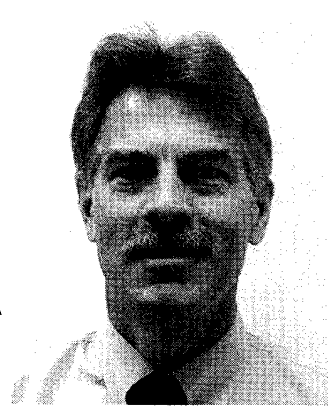

Twenty-five years ago, I graduated from medical school and embarked upon a career in Urology and Pediatric Urology. Vesicoureteral reflux (VUR) was a commonly diagnosed condition, generally identified after a child was evaluated for a urinary tract infection. Around this time, prenatal ultrasonography was first being introduced and renal anomalies were increasingly recognized. The findings of antenatal hydronephrosis raised the spectrum that vesicoureteral reflux was present and routine postnatal evaluation was employed.

These two situations, in which an infant or child is found to have VUR after presenting with a urinary tract infection or a fetus is identified with hydronephrosis and subsequently found to have VUR are two very different situations. The goal in the management of VUR is to prevent pyelonephritis which can be deleterious to the kidney. How one approaches each of these populations should be very different. In fact, it has taken considerable time to see approaches are changing. One current strategy includes a top-down approach, in which a DMSA renal scan is obtained to confirm the presence of pyelonephritis or a parenchymal abnormality before further evaluation is performed. Recent data has even questioned the benefits of antibiotic prophylaxis once VUR is identified. With healthcare costs continuing to escalate, a rational approach to the identification and management of VUR is incumbent.

Dr. Michael Carr is an attending Urologist at Children's Hospital of Philadelphia and an associate professor of Urology and surgery at the University of Pennsylvania, School of Medicine.

I received a Bachelor of Science at John Carroll University in Cleveland, Ohio, obtained a Ph:D in biochemistry at Ohio State University. I obtained my medical degree at the University of Cincinnati where I completed two years of surgical training and then went on to Boston University for my Urology training. I completed a fellowship in pediatric Urology at Boston Children's Hospital. Since 1998 I have been at Children's Hospital of Philadelphia. I have specialty interests in complex congenital urinary tract and urogenital anomalies, exstrophy and epispadias, neuropathic bladder and urinary incontinence as well as hydronephrosis and ureteral-pelvic junction obstruction. 